\title{
Crescimento vegetativo e produtivo de duas cultivares de morango sob épocas de plantio em ambiente subtropical ${ }^{1}$
}

\author{
Vegetative growth and production of two strawberry cultivars for different planting \\ times in a subtropical environment
}

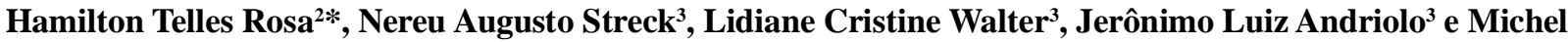 \\ Rocha da Silva $^{3}$
}

\begin{abstract}
RESUMO - O crescimento adequado das folhas resulta em incremento na área foliar, o que permite maior interceptação de radiação solar e em conseqüência maior atividade fotossintética e maior produtividade da cultura em diferentes épocas de plantio. Os objetivos neste trabalho foram obter equações para estimativa da área foliar a partir de dimensões lineares do limbo foliar, estabelecer relações alométricas entre área foliar e número de folhas na coroa primária e determinar a produtividade de frutos em diferentes datas de plantio em duas cultivares de morangueiro. $\mathrm{O}$ experimento foi conduzido na área experimental do departamento de Fitotecnia da Universidade Federal de Santa Maria, em Santa Maria, RS, com as cultivares Arazá e Yvapitá. Foram realizadas seis datas de plantio: 03/04/2008, 07/05/2008, 02/06/2008, 02/02/2009, 02/04/2009 e 02/06/2009. O delineamento experimental utilizado foi blocos ao acaso com quatro repetições (parcelas de 30 plantas). Em cada parcela seis plantas foram marcadas para determinação semanal do número e área de folhas na coroa primária e massa fresca e número de frutos por planta. O modelo potência caracterizou satisfatoriamente a relação alométrica entre evolução da área foliar e número de folhas acumulado na coroa primária. A produção de frutos foi influenciada pela época de plantio, de modo que plantios no início do período recomendado pela EMBRAPA (abril) propiciam maior área foliar no início da floração e maior potencial produtivo, especialmente em anos com elevada radiação solar na primavera como foi o ano de 2008.
\end{abstract}

Palavras-chave: Morango. Análise foliar. Cultivos agrícolas. Rendimento.

\begin{abstract}
The proper growth of leaves results in an increase in leaf area, which allows for greater interception of solar radiation, and consequently greater photosynthetic activity and better crop productivity for different planting times. The objectives of this work were to obtain equations in order to estimate leaf area from the linear dimensions of the leaf blades, to establish allometric relationships between the leaf area and the number of leaves in the primary crown, and to determine the productivity of fruits for different planting dates of two strawberry cultivars. The experiment was carried out at the experimental area of the Department of Plant Science, at the Federal University of Santa Maria, in Santa Maria, Rio Grande do Sul, with the Araza and Yvapitá cultivars. Plants were sown on six dates: 03/04/2008, 07/05/2008, 02/06/2008, 02/02/2009, 02/04/2009 and 02/06/2009. The experimental design used was of randomised blocks with four replications (plots of 30 plants each). In each plot, six plants were tagged for weekly determination of the number and area of leaves in the primary crown, and the fresh weight and number of fruits per plant. The power model satisfactorily characterised the allometric relationship between the development of the leaf area and the number of leaves accumulated in the primary crown. Fruit production was influenced by planting time, so that early planting in the period recommended by EMBRAPA (April) provides greater leaf area at the beginning of flowering, and a higher yield potential, especially in years with high solar radiation in the spring, as happened in 2008.
\end{abstract}

Key words: Strawberry. Leaf analysis. Agricultural crops. Yield.

\footnotetext{
* Autor para correspondência

${ }^{1}$ Recebido para publicação em 20/03/2012; aprovado em 08/02/2013

Parte da Dissertação de Mestrado do primeiro autor, apresentada ao Programa de Pós-Graduação em Agronomia da Universidade Federal de Santa Maria/UFSM, Bolsa CAPES

${ }^{2}$ Departamento Fitotecnia/UFSM, Santa Maria-RS, Brasil, hamiltontellesrosa@ gmail.com

${ }^{3}$ Departamento Fitotecnia/UFSM, Santa Maria-RS, Brasil, nstreck2@yahoo.com.br, lidianewalter@gmail.com, jeronimoandriolo@gmail.com, michelrs@live.com
} 


\section{INTRODUÇÃO}

Produzido e apreciado nas mais variadas regiões do mundo, o morangueiro (Fragaria $x$ ananassa) é considerado uma das espécies de maior expressão econômica entre as pequenas frutas (RIGON et al., 2005). A produção mundial de morango gira em torno de 3,1 milhões de toneladas por ano (UNITED STATES DEPARTMENT OF AGRICULTURE, 2010), sendo o Brasil o segundo maior produtor da América Latina com uma produção anual superior a 90 mil toneladas (SANTOS; MEDEIROS, 2003).

A fase vegetativa do ciclo do morangueiro inclui a formação de estolões, a emissão de folhas e a formação de coroas secundárias, e a fase reprodutiva abrange a indução floral, iniciação e surgimento das flores, crescimento e maturação dos frutos (DARROW, 1966). Estas fases interagem de forma complexa com o ambiente e o conhecimento desta interação é a base para seleção de cultivares adaptadas, no zoneamento e na modelagem matemática desta cultura.

Durante a fase vegetativa, o crescimento das folhas consiste principalmente no incremento na área foliar (AF), o qual determina a evolução do índice de área foliar (IAF), um dos parâmetros fisiológicos mais utilizados em estudos de análise de crescimento das plantas e em modelos de simulação da produtividade de diversas culturas agrícolas, uma vez que o IAF influencia diretamente na interceptação de radiação solar e fotossíntese pelo dossel e assim determina, em grande parte, a produtividade da cultura (STRECK et al., 2003a; STRECK et al., 2005a, b; XUE et al., 2004;). Além disso, o IAF tem estreita relação com o consumo de água pela cultura e o conhecimento da sua variação pode ter aplicações em modelos de evapotranspiração, fotossíntese e em simulações do crescimento vegetativo (STRECK et al., 2003b).

Relações entre crescimento e desenvolvimento de diferentes órgãos do indivíduo são denominadas relações alométricas e são úteis para conhecer e determinar as interações entre os vários órgãos da planta (PORTELA; SANTOS, 2003). Um método empírico indireto de estimativa da $\mathrm{AF}$ envolve o estabelecimento de relações alométricas entre AF e número de folhas. Este tipo de relação já foi estabelecida em arroz (OKAMI et al., 2012), cana-de-açúcar (SINCLAIR et al., 2004), tomate (PIVETTA et al., 2007) e berinjela (MALDANER et al., 2009) e diversas culturas de grãos (SADRAS; EGLI, 2008) e espécies arbóreas (PORTELA; SANTOS, 2003).

O morangueiro é uma cultura pouco estudada nas condições subtropicais, especialmente no Rio Grande do Sul. O calendário de cultivo de morango nas regiões subtropicais compreende o plantio das mudas no início do outono, colheita na primavera até o início do verão e produção de mudas (por estolões) durante o verão, pois temperaturas baixas e fotoperíodo curto estimulam a diferenciação floral, enquanto temperaturas elevadas e fotoperíodolongo estimulam o estolonamento(HEIDE, 1977). Assim, estudos com diferentes cultivares e épocas de plantio são importantes para produção precoce, o que possibilita maior preço de comercialização, e altas produtividades de frutas. Além disso, experimentos com épocas de plantio fornecem bases de dados para calibração e avaliação de modelos matemáticos. Assim, os objetivos deste trabalho foram obter equações para estimativa da área foliar a partir de dimensões lineares do limbo foliar, estabelecer relações alométricas entre área foliar e número de folhas na coroa primária e determinar a produtividade de frutos em diferentes datas de plantio em duas cultivares de morangueiro.

\section{MATERIAL E MÉTODOS}

Oexperimento foi conduzido, durante os anos de 2008 e 2009, na área experimental do Departamento de Fitotecnia da Universidade Federal de Santa Maria, Santa Maria, RS

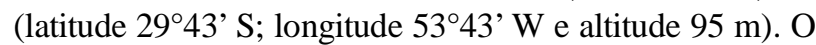
clima local, segundo a classificação climática de Köppen, pertence ao tipo fundamental $\mathrm{Cfa}$, subtropical úmido com verões quentes e sem estação seca definida (HELDWEIN; BURIOLe STRECK, 2009). O solo da área experimental é uma transição entre a Unidade de Mapeamento São Pedro (Argissolo Vermelho distrófico arênico) e a Unidade de Mapeamento Santa Maria (Argissolo Bruno acinzentado alítico típico) (EMPRESA BRASILEIRA DE PESQUISA AGROPECUÁRIA, 2006).

As cultivares Arazá e Yvapitá, selecionadas pelo programa de melhoramento genético do INIA-Uruguai e adaptadas para cultivo em região subtropical, foram utilizadas neste estudo por apresentarem características distintas quanto à precocidade de produção. A cultivar Arazá é considerada precoce enquanto a cultivar Yvapitá produz mais tardiamente sendo também recomendada para a produção orgânica, devido à sua rusticidade (GIMENEZ, 2007).

Foram realizadas seis datas de plantio durante os dois anos: 03/04/2008, 07/05/2008, 02/06/2008, 02/02/2009, $02 / 04 / 2009$ e $02 / 06 / 2009$. As datas foram selecionadas para terem-se plantas em crescimento e desenvolvimento antes, durante e após o período habitual para o plantio no Estado, que ocorre durante o outono, entre abril e maio (ALMEIDA et al., 2009); sendo assim as plantas expostas às diferentes condições ambientais durante a estação de cultivo. As mudas foram produzidas a partir de pontas de estolões coletadas de plantas matrizes mantidas em campo e ficaram aproximadamente um mês em dispositivos do tipo câmara úmida com microaspersão, em bandejas de 128 células preenchidas com o substrato comercial Plantimax $^{\circledR}$, em sistema hidropônico sob estufas cobertas com polietileno transparente com laterais abertas. 
Após o período de enraizamento, as mudas com 4 a 6 folhas foram transplantadas para canteiros com $1,2 \mathrm{~m}$ de largura e $20 \mathrm{~m}$ de comprimento. A densidade de plantio foi de 10 plantas $\mathrm{m}^{-2}$ dispostas no espaçamento de $0,4 \mathrm{~m}$ entre plantas na fila e $0,25 \mathrm{~m}$ entre fileiras. O preparo dos canteiros foi realizado com uma encanteiradeira mecânica. A adubação de base nos canteiros foi realizada com NPK nas concentrações de 20; 60 e 50 kg ha-1, respectivamente. Após adubação e instalação do sistema de irrigação os canteiros foram cobertos com mulching plástico preto de $30 \mu \mathrm{m}$. A irrigação foi realizada através de duas mangueiras gotejadoras sobre o solo com distância entre emissores de $20 \mathrm{~cm}$ e vazão de 1,4 litros hora ${ }^{-1}$. Nas duas primeiras semanas após o transplante das mudas, foi feita irrigação diariamente para reduzir o estresse de transplante, com lâmina variável e de acordo com a demanda diária da cultura, com base na evaporação do tanque Classe A, medida em estação meteorológica, distante a aproximadamente $150 \mathrm{~m}$ do experimento. Após este período inicial de estabelecimento das mudas, a quantidade de precipitação pluviométrica e a baixa evaporação da água do solo devido ao mulching mantiveram a umidade do solo dos canteiros suficiente para atender a demanda hídrica, não sendo realizadas irrigações suplementares. A partir da floração foram aplicadas, mensalmente, soluções nutritivas por fertirrigação, na dose de 1 litro de solução nutritiva por planta, levando-se em consideração a extração mensal de nutrientes da cultura, proposta por Andriolo et al. (2009). Esta metodologia (irrigação e fertirrigações) é comumente realizada pelos agricultores locais.

O delineamento experimental foi blocos ao acaso com quatro repetições, sendo cada parcela composta por 30 plantas. Após o transplante, seis plantas em cada parcela foram marcadas com arame colorido nas quais foram contados, semanalmente, o número de folhas (trifólios) expandidas na coroa primária e, em duas destas plantas marcadas, quinzenalmente foram medidos o comprimento e a largura do folíolo central das folhas expandidas para estimativa da área foliar fotossinteticamente ativa. Uma folha foi considerada expandida quando os lóbulos de seus folíolos não mais se tocavam.

Para determinação da área foliar da coroa primária (AF) foram coletados 100 trifólios de cada cultivar. A área de cada trifólio foi escaneada, transformada em pixels e relacionada com a quantidade de pixels de uma superfície com área conhecida. Depois, foram determinadas equações de regressão linear simples entre $\mathrm{AF}$ e comprimento $(\mathrm{C})$ do folíolo central, entre AF e largura (L) do folíolo central e entre $\mathrm{AF}$ e o produto $\mathrm{CxL}$ do folíolo central para cada cultivar, a fim de estimar a área de folhas individuais. A equação usada para o cálculo da AF das plantas marcadas no experimento foi a que apresentou maior coeficiente de determinação $\left(\mathrm{R}^{2}\right)$.
Para estabelecer relações alométricas entre AF e NF, ajustou-se o modelo não linear do tipo potência $\mathrm{y}=\mathrm{aX} \mathrm{X}^{\mathrm{b}}$ aos dados de $\mathrm{AF}$ acumulada $\left(\mathrm{cm}^{2}\right)$ na coroa primária $(\mathrm{Y})$ e $\mathrm{NF}(\mathrm{X})$ na coroa primária de duas plantas, sendo "a" e "b" coeficientes ajustados que representam, respectivamente, a área da primeira folha $\left(\mathrm{cm}^{2}\right)$ e a taxa de acúmulo de área para cada folha adicional $\left(\mathrm{cm}^{2} \mathrm{~cm}^{-2}\right)$ na coroa primária. $\mathrm{O}$ modelo potência foi escolhido por ser realístico do ponto de vista ecofisiológico, uma vez que descreve a evolução da área de cada folha com o número de folhas acumulado de forma não linear, tendo sido usado anteriormente em outras culturas agrícolas (MALDANER et al., 2009; PIVETTA et al., 2007; SINCLAIR et al., 2004). Os dados usados para ajuste do modelo potência como modelo das relações alométricas entre NF e AF foram da coroa primária do período entre o plantio até a última colheita dos frutos.

As colheitas foram realizadas nas seis plantas marcadas em cada parcela quando os frutos apresentavam no mínimo $75 \%$ da epiderme com a coloração característica da cultivar. Os frutos colhidos com peso superior a 10 gramas (consideradas comerciais) foram contados e pesados em balança de precisão de 0,01 g. Foi calculada a produtividade precoce (frutos colhidas até o final de setembro) e a produtividade total (soma de todo o período de colheita). O período de colheita dos frutos foi de 02/07 a 03/12/2008 na primeira época de plantio e de 22/07 a 03/12/2008 nas outras duas épocas de plantio do ano de 2008. No ano de 2009 o período de colheita foi de 13/05 a 21/11/2009, de $05 / 06$ a 21/11/2009 e de $31 / 08$ a 21/11/2009, respectivamente, nas três datas de plantio realizadas. Os componentes da produtividade dos frutos (massa fresca de frutos e número de frutos por planta) foram submetidos à análise estatística considerando-se um experimento bifatorial com duas fontes de variação (datas de plantio com seis níveis e cultivares com dois níveis), utilizando-se o teste $\mathrm{F}$ e, posteriormente, o teste de Tukey ao nível de 5\%. Para a estimativa da área foliar a partir das dimensões lineares e para a relação entre a área foliar (variável x) e massa fresca de frutos (variável y) foi realizada análise de regressão simples $(\mathrm{p}<0,05)$. Para as relações alométricas foi realizada análise de regressão não linear (modelo potência, $\mathrm{p}<0,05$ ).

\section{RESULTADOS E DISCUSSÃO}

Durante o período de emissão de folhas em 2008 a temperatura mínima (TMIN) e máxima (TMAX) absolutas foram 0,2 e $35{ }^{\circ} \mathrm{C}$ em 17/06 e 19/09 respectivamente, e no ano de 2009 foram de $-2,2{ }^{\circ} \mathrm{C}$ em $25 / 07$ e $38,5{ }^{\circ} \mathrm{C}$ em 02/11. Nos dois anos, nos meses de junho a agosto foram freqüentes os dias com TMIN do ar próxima a $0{ }^{\circ} \mathrm{C}$ enquanto nos meses de novembro, fevereiro e março 
foram freqüentes os dias em que a TMAX do ar foi maior que $32{ }^{\circ} \mathrm{C}$. $\mathrm{O}$ ano de 2009 se caracterizou por um inverno mais frio que o ano de 2008, com 32 dias de TMIN igual ou inferior a $5{ }^{\circ} \mathrm{C}$, enquanto que 2008 teve 19 dias com TMIN igual ou inferior a $5{ }^{\circ} \mathrm{C}$. No segundo semestre de 2008 e especialmente no primeiro semestre de 2009, houve menos dias com chuva, devido ao fenômeno La Niña, enquanto no segundo semestre de 2009 houve mais dias de chuva devido à ocorrência do fenômeno El Niño.

A regressão entre a área foliar e o produto do comprimento (C) e da largura (L) resultou no ajuste de modelos com maior coeficiente de determinação $\left(\mathrm{R}^{2}\right)$. As equações que melhor estimaram a área de folhas individuais para as cultivares Arazá e Yvapitá estão na Figura 1. O R ${ }^{2}$ dos modelos de estimativa de área foliar foram de 0,95 e 0,94 para as cultivares Arazá e Yvapitá, respectivamente, e os coeficientes angulares das regressões são altamente significativos ( $\mathrm{p}<0,000001)$ demonstrando que as equações permitem boas estimativas da área foliar em morangueiro. Por terem sido consideradas folhas de diferentes tamanhos para calibrar as equações, estes modelos têm a capacidade de predizer a área foliar com elevada precisão, apenas com a medição do comprimento e da largura do folíolo central. Pires, Folegatti e Passos (1999), testando métodos de estimativa de área foliar do morangueiro por meio não destrutivo obtiveram melhores resultados quando analisaram comprimento e largura conjuntamente. Segundo Busato et al. (2010) modelos de estimativa de área foliar com medidas não destrutivas, obtidas diretamente no campo, são ferramentas adequadas e úteis para predição da área foliar.

Na Figura 2 estão as relações alométricas entre área e o número de folhas acumuladas na coroa primária de ambas as cultivares de morangueiro nas seis datas de plantio. O R $\mathrm{R}^{2}$ variou de 0,75 a 0,88 , indicando bom ajuste do modelo potência para caracterizar a relação alométrica entre AF e NF na coroa primária. Não foi possível ajustar uma equação única para as duas cultivares, devido às diferenças morfológicas nas folhas das cultivares estudadas. A cultivar Yvapitá apresentou em todas as datas de plantio, folhas significativamente maiores em relação à cultivar Arazá. Diferenças entre genótipos na relação entre área foliar e o NF também foram relatadas em cana-de-açúcar (SINCLAIR et al., 2004) e de tomateiro (PIVETTA et al., 2007).

Na cultivar Arazá, o ajuste foi similar nos anos de 2008 e 2009, com $\mathrm{R}^{2}$ de 0,85 e 0,88 , respectivamente (Figura 2A, 2C), enquanto na cultivar Yvapitá o ajuste foi bom no primeiro ano, com $\mathrm{R}^{2}$ de 0,86 (Figura 2B) e no segundo ano a dispersão dos pontos foi maior, com $\mathrm{R}^{2}$ de 0,75 (Figura 2D), devido a um maior desvio dos pontos do plantio em 02/06/2009, provavelmente em função da menor radiação solar durante a primavera de 2009, que resultou em menos e maiores folhas. Quando foram agrupados os dados dos dois anos (seis datas de plantio) para cada cultivar (Figura 2E e 2F), o ajuste teve um $\mathrm{R}^{2}$ de 0,81 e 0,79 para Arazá e Yvapitá, respectivamente, tendo os dados maior dispersão em relação á curva do modelo potência, como esperado, já que as condições meteorológicas foram distintas durante a emissão de folhas entre as seis datas de plantio nos dois anos, mas a tendência geral dos dados observados foi similar entre as datas de plantio.

Os dados combinados nas Figuras 2E e 2F também indicam a diferença de área foliar entre as duas cultivares. Em 20 folhas da cultivar Arazá a AF, na maioria das datas de plantio, foi inferior a $1.000 \mathrm{~cm}^{2}$ planta $^{-1} \operatorname{coroa}^{-1}$ (Figura 2E) e na cultivar Yvapitá no mesmo número de folhas a $\mathrm{AF}$

Figura 1 - Relação entre a área foliar do trifólio $\left(\mathrm{cm}^{2}\right)$, e o produto do comprimento pela largura do folíolo central nas duas cultivares de morangueiro Arazá (A) e Yvapitá (B), cultivados em Santa Maria, RS
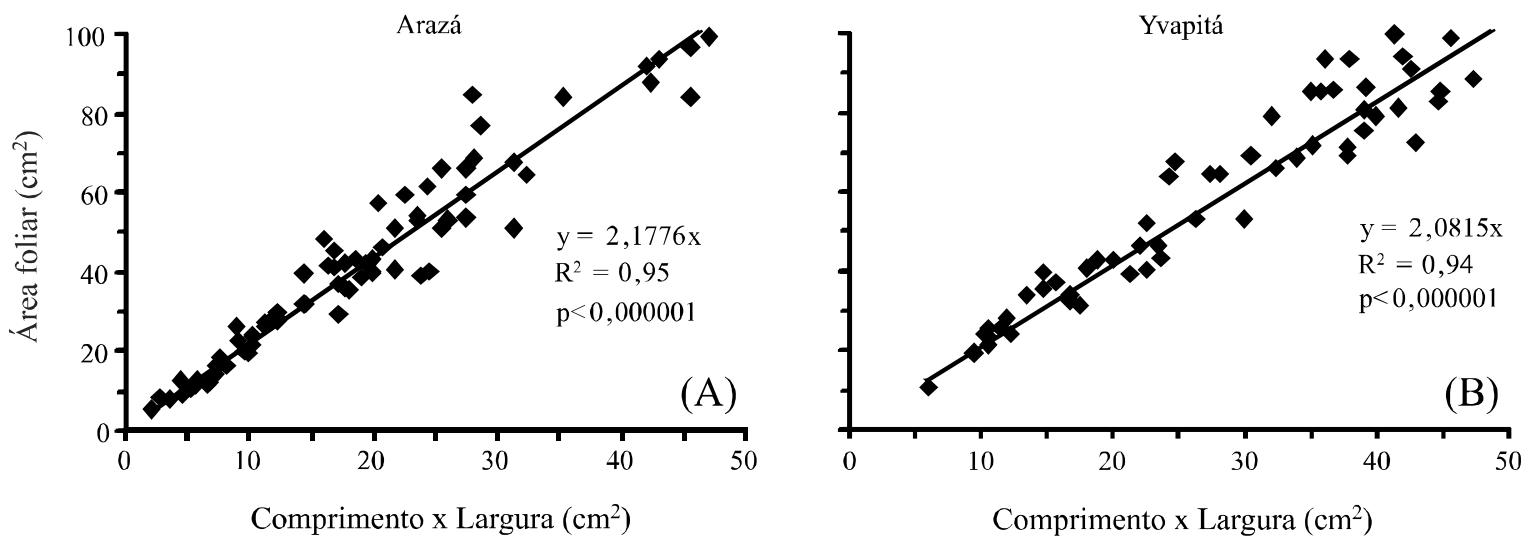

Rev. Ciênc. Agron., v. 44, n. 3, p. 604-613, jul-set, 2013 
variou de 1.000 e $1.500 \mathrm{~cm}^{2}$ planta $^{-1}$ coroa $^{-1}$ na maioria das datas de plantio (Figura 2F). Os resultados deste estudo indicam uma alternativa para estimar a AF em morangueiro a partir do NF, já que esta metodologia tem como vantagem a facilidade de contagem do NF quando comparada com as medições de $\mathrm{AF}$ a campo que são mais trabalhosas e exigem maior tempo e mão de obra (PIVETTA et al., 2007).

Figura 2 - Relação alométrica entre área de folhas verdes (AF) e número de folhas acumuladas (NF) na coroa primária até a floração em duas cultivares de morangueiro em três datas de plantio no ano de 2008 para as cultivares Arazá (A) eYvapitá (B), e no ano de 2009 para 'Arazá' (C) e Yvapitá (D), e em seis datas de plantio nos dois anos (E, F). A equação ajustada é o modelo potência. Santa Maria, RS
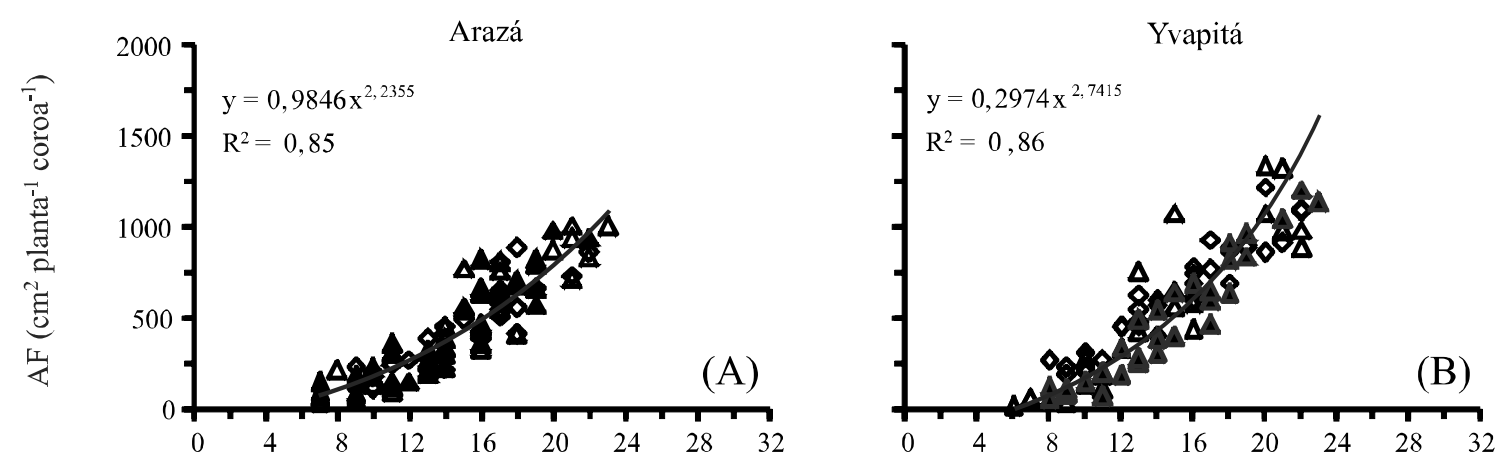

$\boldsymbol{\Delta}_{03 / 04 / 2008} \boldsymbol{\diamond}_{07 / 05 / 2008} \boldsymbol{\Delta}_{02 / 06 / 2008}$
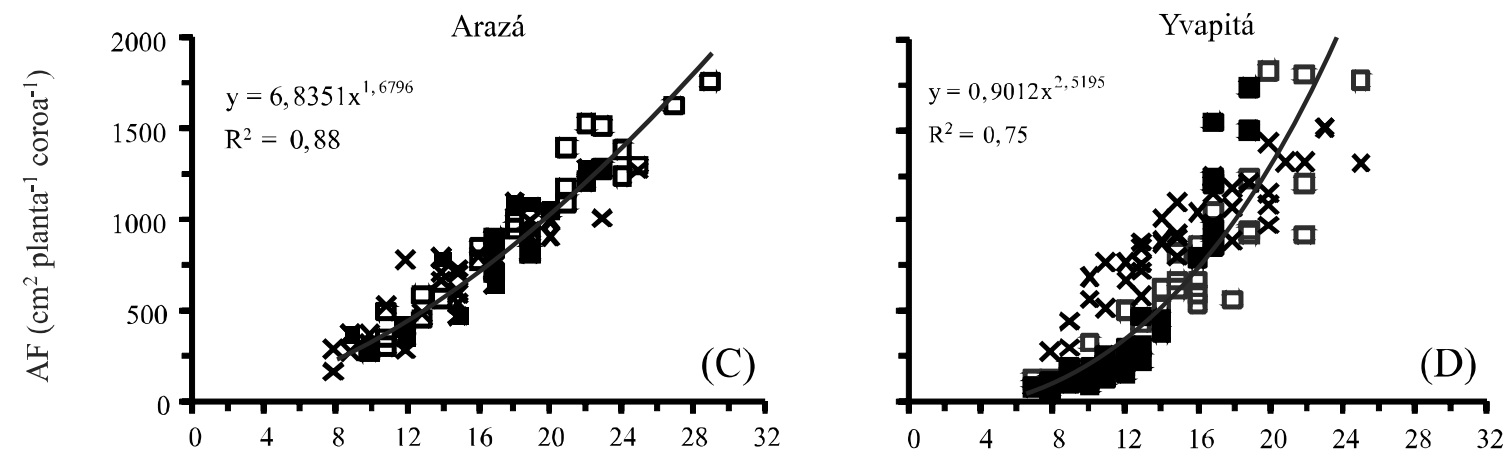

$\boldsymbol{口}_{02 / 02 / 2009} \boldsymbol{X}_{02 / 04 / 2009} \boldsymbol{a}_{02 / 06 / 2009}$

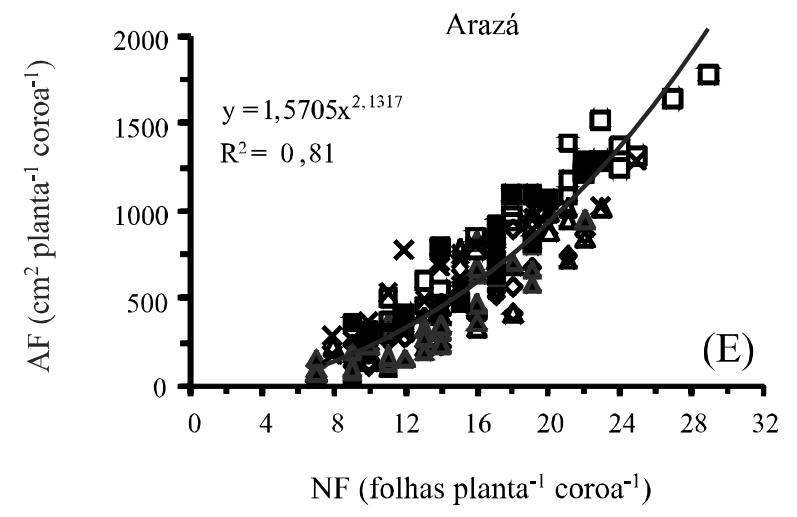

$\boldsymbol{\Psi}_{03 / 04 / 2008} \diamond_{07 / 05 / 2008} \boldsymbol{\Delta}_{02 / 06 / 2008}$

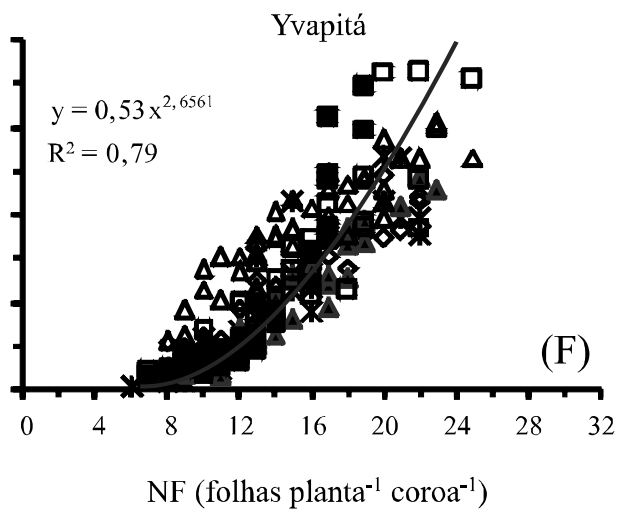

$\boldsymbol{口}_{02 / 02 / 2009} \boldsymbol{\Delta}_{02 / 04 / 2009}$ 
Quanto à produção dos frutos $\left(\mathrm{g}\right.$ planta $\left.{ }^{-1}\right)$, entre os fatores principais (cultivar e data de plantio), o maior quadrado médio foi do fator data de plantio, o que indica que a variação da produção dos frutos é mais afetada pelo ambiente do que pela constituição genética das duas cultivares de morangueiro. Na Tabela 1 estão os resultados da análise de variância das variáveis massa fresca e número de frutos por planta. Como houve interação significativa dos fatores cultivar $\mathrm{x}$ data de plantio, a análise foi desdobrada e apresentada nas Tabelas 2 e 3.

A cultivar Arazá produziu maior número de frutos precocemente embora nos plantios de 07/05/2008 e 02/06/2009 essa diferença não foi significativa (Tabela 2). Na média das datas de plantio a cultivar Arazá produziu 174 g planta ${ }^{-1}$ enquanto a cultivar Yvapitá produziu $76 \mathrm{~g} \mathrm{planta}^{-1}$. Ao relacionar os valores médios de massa fresca de frutos, observa-se que a produção precoce por planta de frutos da cultivar Arazá foi 128,9\% superior ao da cultivar Yvapitá. Essa produção precoce da cultivar Arazá foi superior à citada por Janisch et al. (2008) que, para esta cultivar conduzida sob túneis baixos obtiveram valores de produção precoce variando de 49,05 a 109,7 $\mathrm{g}_{\text {planta }}{ }^{-1}$ nos plantios realizados em 15/04/2007 e 15/03/2007, respectivamente. Para os respectivos autores, o impacto da época de plantio na produção de frutos é mais expressivo na produção precoce, período em que os preços de comercialização são mais atrativos devido à menor oferta no produto.
A massa fresca dos frutos por planta da produção total não diferiu entre as cultivares nos três plantios durante o ano de 2008 (Tabela 3) e no ano de 2009 a cultivar Arazá teve maior massa fresca de frutos do que a cultivar Yvapitá nas três datas de plantio, não havendo diferença significativa entre as cultivares na data de plantio de 02/06/2009. A produção média de frutos das três datas de plantio em 2009 foi inferior à média das três datas de plantio do ano de 2008.

Nos plantios realizados até abril nos dois anos (03/04/2008, 02/02/2009 e 02/04/2009), a cultivar Arazá produziu maior número total de frutos por planta e nos plantios de maio a junho sua produção foi similar à produção da cultivar Yvapitá (Tabela 2). Esses resultados indicam que as duas cultivares são distintas na produção, com a cultivar Arazá produzindo frutos com menor massa fresca, porém em maiores quantidades, enquanto a cultivar Yvapitá se caracteriza por produzir um número inferior de frutos, contudo com maior massa fresca, indicando a interação compensatória do tamanho do compartimento de dreno de fotoassimilados destinados ao crescimento reprodutivo em morango. Essa interação compensatória entre número e o tamanho de frutos havia sido citada por Darrow (1966). A cultivar Yvapitá também produziu diversos frutos com massa fresca superior a $50 \mathrm{~g}$, o que pode qualificar essa cultivar para produção de frutos diferenciados para consumo in natura.

Tabela 1 - Resumo da análise de variância para as variáveis massa fresca e número de frutos em morangueiro. Santa Maria, RS, 2008 , 2009

\begin{tabular}{|c|c|c|c|c|}
\hline \multirow{2}{*}{ Fonte de variação } & G.L. & S.Q. & Q.M. & $\mathrm{F}$ \\
\hline & \multicolumn{4}{|c|}{ Massa fresca de frutos } \\
\hline Cultivar (F1) & 1 & 18370,74 & 18370,73 & $4,536^{*}$ \\
\hline Data de plantio (F2) & 5 & 814865,19 & 162973,03 & $40,24 * *$ \\
\hline Interação entre F1 e F2 & 5 & 91900,09 & 18380,01 & $4,538 * *$ \\
\hline Tratamentos & 11 & 925136,02 & 84103,27 & $20,77 * *$ \\
\hline Blocos & 3 & 6930,58 & 2310,19 & $0,5704^{\mathrm{ns}}$ \\
\hline Resíduo & 33 & 133650,97 & 4050,02 & \\
\hline Total & 47 & 1065717,58 & & \\
\hline \multicolumn{5}{|c|}{ Número de frutos por planta } \\
\hline Cultivar (F1) & 1 & 342,22 & 342,22 & $20,54 * *$ \\
\hline Data de plantio (F2) & 5 & 3113,85 & 622,77 & $37,69 * *$ \\
\hline Interação entre F1 e F2 & 5 & 386,03 & 77,20 & $4,635^{* *}$ \\
\hline Tratamentos & 11 & 3842,11 & 349,28 & $20,97 * *$ \\
\hline Blocos & 3 & 31,33 & 10,44 & $0,5704^{\text {ns }}$ \\
\hline Resíduo & 33 & 549,59 & 16,65 & \\
\hline Total & 47 & 4423,03 & & \\
\hline
\end{tabular}

**significativo ao nível de $1 \%(\mathrm{p}<0,01)$; ${ }^{*}$ significativo ao nível de $5 \%(0,01 \leq \mathrm{p}<0,05) ;{ }^{\text {ns }}$ não significativo $(\mathrm{p} \geq 0,05)$ 
Tabela 2 - Médias de produção precoce (até 30 de setembro) de frutos comerciais de duas cultivares de morangueiro em seis datas de plantio. Santa Maria, RS, 2008, 2009

\begin{tabular}{lcccccc}
\hline \multirow{2}{*}{ Cultivar } & $03 / 04 / 2008$ & $07 / 05 / 2008$ & $02 / 06 / 2008$ & $02 / 02 / 2009$ & $02 / 04 / 2009$ & $02 / 06 / 2009$ \\
\cline { 2 - 6 } & \multicolumn{6}{c}{ Massa fresca de frutos $\left(\mathrm{g}\right.$ planta $\left.{ }^{-1}\right)$} \\
\hline Arazá & $345,5 \mathrm{aA} *$ & $58,7 \mathrm{aC}$ & $101,3 \mathrm{aC}$ & $261,9 \mathrm{aAB}$ & $230,7 \mathrm{aB}$ & $46,5 \mathrm{aC}$ \\
Yvapitá & $143,1 \mathrm{bA}$ & $46,0 \mathrm{aAB}$ & $41,7 \mathrm{bB}$ & $84,8 \mathrm{bAB}$ & $118,8 \mathrm{bAB}$ & $21,4 \mathrm{aB}$ \\
\hline \multicolumn{6}{c}{$\mathrm{CV}(\%) 37,5$} \\
\hline \multicolumn{7}{c}{ Número de frutos por planta } \\
\hline Arazá & $57,8 \mathrm{aA}$ & $28,5 \mathrm{aB}$ & $28,2 \mathrm{aB}$ & $21,5 \mathrm{aB}$ & $19,7 \mathrm{aB}$ & $3,8 \mathrm{aC}$ \\
Yvapitá & $33,9 \mathrm{bA}$ & $27,7 \mathrm{aA}$ & $22,6 \mathrm{aA}$ & $6,8 \mathrm{bB}$ & $7,1 \mathrm{bB}$ & $1,3 \mathrm{aB}$ \\
\hline \multicolumn{7}{c}{$\mathrm{CV}(\%) 27,6$} \\
\hline
\end{tabular}

* Médias seguidas pela mesma letra minúsculas na vertical e maiúsculas na horizontal não diferem pelo teste Tukey ao nível de 5\% de erro

Tabela 3 - Médias de produção total dos frutos comerciais de duas cultivares de morangueiro em seis datas de plantio. Santa Maria, RS, 2008, 2009

\begin{tabular}{lcccccc}
\hline \multirow{2}{*}{ Cultivar } & \multicolumn{7}{c}{ Datas de plantio } \\
\cline { 2 - 6 } & $03 / 04 / 2008$ & $07 / 05 / 2008$ & $02 / 06 / 2008$ & $02 / 02 / 2009$ & $02 / 04 / 2009$ & $02 / 06 / 2009$ \\
\hline Mrazá & $546,8 \mathrm{aA} *$ & $267,8 \mathrm{aB}$ & $211,3 \mathrm{aBC}$ & $238,9 \mathrm{aBC}$ & $319,4 \mathrm{aB}$ & $121,7 \mathrm{aC}$ \\
Yvapitá & $509,0 \mathrm{aA}$ & $329,5 \mathrm{aB}$ & $264,2 \mathrm{aBC}$ & $118,4 \mathrm{bD}$ & $139,2 \mathrm{bCD}$ & $110,8 \mathrm{aD}$ \\
\hline \multicolumn{7}{c}{ NV́mero de frutos por planta } \\
\hline \multicolumn{7}{c}{24,0} \\
\hline Arazá & $37,5 \mathrm{aA}$ & $17,5 \mathrm{aB}$ & $14,5 \mathrm{aB}$ & $13,7 \mathrm{aBC}$ & $21,7 \mathrm{aB}$ & $8,25 \mathrm{aC}$ \\
Yvapitá & $27,5 \mathrm{bA}$ & $18,1 \mathrm{aB}$ & $15,4 \mathrm{aB}$ & $7,5 \mathrm{bCD}$ & $7,0 \mathrm{bCD}$ & $5,8 \mathrm{aD}$ \\
\hline \multicolumn{7}{c}{$\mathrm{CV}(\%) 25,2$} \\
\hline
\end{tabular}

* Médias seguidas pela mesma letra minúsculas na vertical e maiúsculas na horizontal não diferem pelo teste Tukey ao nível de 5\% de erro

Comparando-se as datas de plantio em cada ano de cultivo, a massa fresca e o número de frutos por planta foram maiores nos plantios de início de abril e diminuíram em plantios anteriores e posteriores a esta época nos dois anos de cultivo nas duas cultivares, salvo para número de frutos por planta da cultivar Yvapitá que não diferiu estatisticamente entre as datas de plantio de fevereiro e abril (Tabela 3). No único plantio anterior a abril (02/02/2009), as plantas emitiram muitos estolões no início do ciclo de desenvolvimento, o que significa investimento elevado de fotoassimilados em drenos de crescimento vegetativo que competiram com o crescimento reprodutivo mais tarde. Na prática, os produtores de morango no RS devem evitar plantios tão antecipados, sob pena de ter reduzido o potencial de produção.
Os resultados, exceto os do plantio de 02/02/2009, evidenciam a existência de uma relação entre a produtividade dos frutos e área foliar das plantas no inicio do crescimento reprodutivo. Tal relação tem bases ecofisiológicas já que uma maior área fotossintetizante intercepta mais radiação solar (TAIZ; ZEIGER, 2009) e, portanto, é realística para que se possa inferir sobre a época de plantio que proporciona a maior produtividade de frutos por planta. Na Figura 3 é apresentada a relação entre a produtividade dos frutos por planta e a área de folhas verdes na coroa primária no início da floração das duas cultivares nas diferentes datas de plantio (exceto em 02/02/2009). Em 2008, a relação foi boa, com coeficientes angulares significativos nas duas cultivares $(\mathrm{p}<0,00015$ e $\mathrm{p}<0,00013$ para as cultivares Arazá e Yvapitá, respectivamente e ambas com $\mathrm{R}^{2}$ de 0,78) (Figura 3A e 3B). No ano de 2009, a relação também 
foi boa para a cultivar Arazá, com coeficiente angular significativo $(\mathrm{p}<0,00225)$ e $\mathrm{R}^{2}$ de 0,81 (Figura 3C), mas não foi boa $\left(\mathrm{R}^{2}\right.$ de 0,35 e $\left.\mathrm{p}<0,1235\right)$ para a cultivar Yvapitá (Figura 3D), ou seja, a relação se repete entre anos para a cultivar Arazá, mas não para a cultivar Yvapitá. Esta relação é alterada pelo ambiente, no sentido de que em um ano em que a disponibilidade de radiação é menor, como em 2009, a produtividade dos frutos nesta cultivar não tem relação dominante com a área fotossintética no início do período reprodutivo, o que se explica fisiologicamente pela baixa de radiação solar devido a muitos dias nublados e chuvosos e quando predominam estas condições meteorológicas durante a estação de cultivo, as folhas são maiores e assim são mais eficientes na interceptação da radiação solar pelo dossel (PENNING de VRIES et al., 1989).

A cultivar Yvapitá tem folhas grandes (Figura 2), e esta característica parece desfavorecer o desempenho agronômico em anos de baixa radiação solar (com muitos dias nublados ou chuvosos). A hipótese é que, nesta cultivar, mesmo com uma maior área foliar para interceptação, a baixa disponibilidade de radiação não favorece a produção de fotoassimilados e ainda, dificulta a ventilação no interior do dossel, aumentando a umidade relativa e proporcionando um microclima favorável ao estabelecimento e propagação de doenças nas folhas e nos frutos. Existe também o efeito de ano na relação entre área fotossintetizante e produção dos frutos, pelo coeficiente angular da relação para a cultivar Arazá, que é 3 vezes maior no ano de 2008 (1,44 g frutos planta $^{-1}$ por $\mathrm{cm}^{2}$ AF planta ${ }^{-1}$, (Figura 3C). Assim, em anos de elevada radiação solar na primavera a planta de morangueiro responde mais à época de plantio do que em anos de baixa radiação solar, com maior produção de massa fresca de frutos para uma mesma área foliar nos plantios no início do período recomendado.

Como o fenômeno El Niño Oscilação Sul tem forte influência na precipitação e na radiação solar no RS (GRIMM; ZILLI, 2009), a implicação destes resultados é que, com a previsão sazonal de El Niño ou La Niña, os agricultores podem ajustar a data de plantio de morangueiro para potencializar a produtividade. Se a previsão para a primavera é de El Niño, o efeito da época de plantio é menos pronunciado ou até inexistente como na cultivar Yvapitá (Tabela 3 e Figura 3D) e se a previsão para a primavera é de La Niña, o efeito da

Figura 3 - Relação entre massa fresca de frutas e área foliar da coroa primária no início da floração em duas cultivares de morangueiro, Arazá (A) e Yvapitá (B) no ano de 2008, e Arazá (C) e Yvapitá (D) no ano de 2009, em cinco datas de plantio. Santa Maria, RS

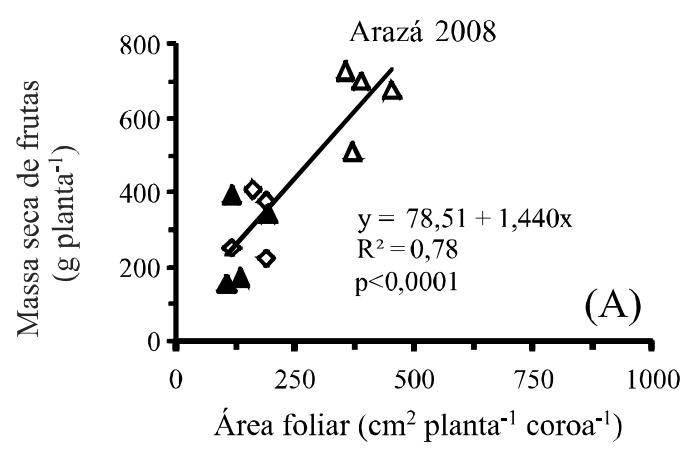

$\boldsymbol{\Delta}_{03 / 04 / 2008} \boldsymbol{\Delta}_{07 / 05 / 2008} \quad \boldsymbol{\Delta}_{02 / 06 / 2008}$

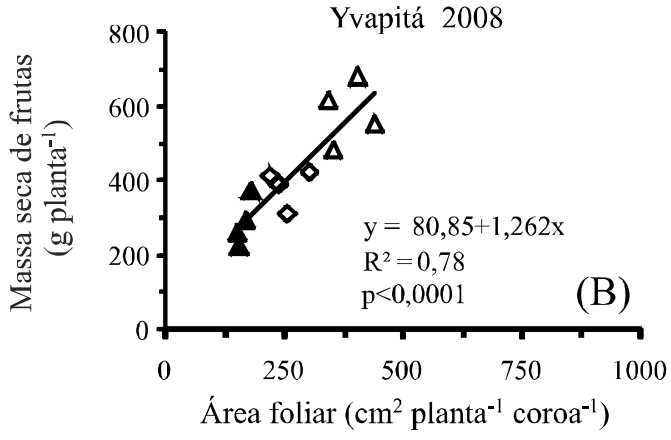

$\Delta 03 / 04 / 2008 \quad \diamond_{07 / 05 / 2008} \quad \Delta 02 / 06 / 2008$

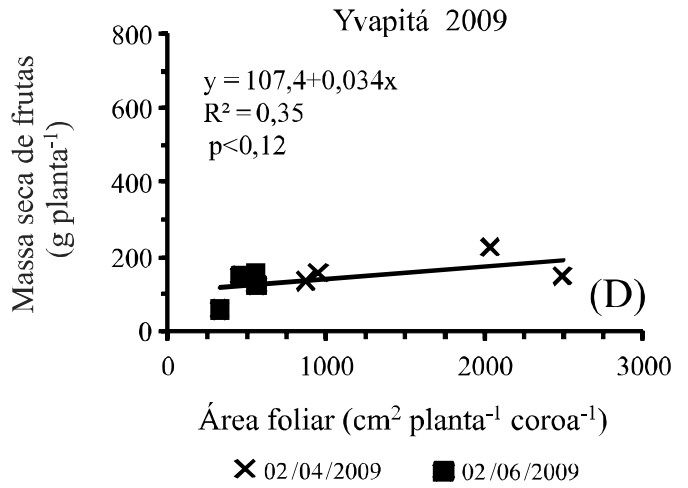


época de plantio no Outono é grande (Figura 3A, 3B), devendo-se fazer o plantio no início de abril.

Os resultados deste estudo contribuem para o avanço do conhecimento do desempenho de morangueiro em ambiente subtropical do Brasil, já que há escassez de estudos e de cultivares adaptadas nesta região do Brasil. Utilizou-se neste trabalho cultivares desenvolvidas e adaptadas às condições Uruguaias, região de clima Subtropical semelhante às regiões onde ocorre a maior parte da produção de morango no Rio Grande do Sul, e que mostraram ter adaptação para a região em estudo. Também como resultados deste estudo são apresentados relações, informações e dados para construir um banco de dados para posteriormente serem usados na calibração e teste de modelos matemáticos para simulação do crescimento, desenvolvimento e produtividade da cultura do morango.

\section{CONCLUSÕES}

1. A estimativa da área foliar das cultivares Arazá e Yvapitá pode ser feita por meio de medições simples de comprimento e largura do folíolo central;

2. O modelo potência é apropriado para caracterizar a relação alométrica entre evolução da área foliar e número de folhas acumulado na coroa primária;

3. Em ambiente subtropical, a produção de frutos em morangueiro é influenciada pela data de plantio.

\section{REFERÊNCIAS}

ALMEIDA, I. R. et al. Potenciais regiões produtoras de morango durante a primavera e verão e riscos de ocorrência de geada na produção de inverno no Estado do Rio Grande do Sul. Pelotas: Embrapa Clima Temperado, 2009. 5 p. (Comunicado Técnico, 229).

ANDRIOLO, J. L. et al. Concentração da solução nutritiva no crescimento da planta, na produtividade e na qualidade de frutas do morangueiro. Ciência Rural, v. 39, n. 3, p. 684-690, 2009.

BUSATO, C. et al. Estimativa da área foliar da batateira, cultivar Atlantic, utilizando dimensões lineares. Revista Ciência Agronômica, v. 41, n. 4, p. 702-708, 2010.

DARROW, G. M. The strawberry: History, breeding and physiology. New York: Holt, Rinehart and Wiston, 1966. 447 p.

EMPRESA BRASILEIRA DE PESQUISA AGROPECUÁRIA. Sistema Brasileiro de Classificação de Solos. 2. ed. Brasília: EMBRAPA Produções de Informações. 2006. 306 p.

GIMENEZ G. Desenvolvimento de novas cultivares de morangueiro. In: SEMINÁRIO SOBRE O CULTIVO HIDRÔPONICO DE MORANGUEIRO. 2007, Santa Maria, RS. Anais... Santa Maria: UFSM, 2007. p. 3-8.
GRIMM, A. M.; ZILLI, M. T. Interannual Variability and Seasonal Evolution of Summer Monsoon Rainfall in South America. Journal of Climate, v. 22, n. 9, p. 2257-2275, 2009.

HEIDE, O. M. Photoperiod and temperature interactions in growth and flowering of strawberry. Physiologia Plantarum, v. 40, n. 40, p. 21-26, 1977.

JANISCH, D. et al. Produção de frutos do morangueiro em diferentes épocas de plantio em Santa Maria, RS. In: CONGRESSO BRASILEIRO DE OLERICULTURA, 48. 2008, Brasília, Anais eletrônicos... Brasília, 2008. Disponível em: < http://www.abhorticultura.com.br/eventosx /trabalhos/ev_2/ A1274_T1739_Comp.pdf > Acesso em: 22 jan. 2012.

HELDWEIN, A. B.; BURIOL, G. A.; STRECK, N. A. O clima de Santa Maria. Ciência \& Ambiente, n. 38, p. 43-58, 2009.

MALDANER, I. C. et al. Filocrono, área foliar e produtividade de frutos de berinjela conduzidas com uma e duas hastes por planta em estufa plástica. Ciência Rural, v. 39, n. 3, p. 671-679. 2009.

OKAMI, M.; KATO, T.; YAMAGISHI, J. Allometric relationship between the size and number of shoots as a determinant of adaptations in rice to water-saving aerobic culture. Field Crops Research, v. 131, p. 17-25, 2012.

PENNING de VRIES, F. W. T. et al. Simulation of ecophysiological processes of growth in several annual crops. Netherlands: Pudoc Wageningen, 1989. 271 p.

PIVETTA, C. R. et al. Emissão e expansão foliar em três genótipos de tomateiro (Lycopersicon esculentum Mill.). Ciência Rural, v. 37, n. 5, p. 1274-1280. 2007.

PIRES, R. C. M.; FOLEGATTI, M. V.; PASSOS, F. A. Estimativa da área foliar do morangueiro. Horticultura Brasileira, v. 17, n. 2, p. 86-90, 1999.

PORTELA, R. C. Q.; SANTOS, F. A. M. dos. Alometria de plântulas e jovens de espécies arbóreas: Copa x Altura. Biota Neotropica, v. 3, n. 2, p. 1-5, 2003.

RIGON,L. etal. Perfil das pequenas frutas. In: ANUÁRIO Brasileiro de Frticultura. Santa Cruz do Sul: Gazeta, 2005. p. 90-97.

SADRAS, V. O.; EGLI, D. B. Seed size variation in grain crops: Allometric relationships between rate and duration of seed growth. Crop Science, v. 48, n. 2, p. 408-416, 2008.

SANTOS, A. M.; MEDEIROS, A. R. M. Morango: Produção. Brasília: EMBRAPA, 2003. 81 p.

SINCLAIR, T. R. et al. Sugarcane leaf area development under field conditions in Florida, USA. Field Crops Research. v. 88, n. 2/3, p. 171-178. 2004.

STRECK, N.A. et al.Improving predictions of developmental stages in winter wheat: a modified Wang and Engel model. Agricultural and Forest Meteorology, v. 115, n. 3/4, p. 139-150. 2003a.

STRECK, N. A. et al. Incorporating a chronology response into the prediction of leaf appearance rate in winter wheat. Annals of Botany, v. 92, p. 181-190, 2003 b.

STRECK, N. A. et al. Estimativa do filocrono em cultivares de trigo de primavera. Revista Brasileira de Agrometeorologia, v. 13 , n. 3, p. 423-429, 2005a. 
STRECK, N. A. et al. Estimativa do plastocrono em meloeiro (Cucumis melo L.) cultivado em estufa plástica em diferentes épocas do ano. Ciência Rural, v. 35, p. 1275-1280. 2005 b.

TAIZ, L.; ZEIGER, E. Fisiologia vegetal. 4. ed. Porto Alegre: Artemed, 2009. 848 p.

UNITED STATES DEPARTMENT OF AGRICULTURE.

Production, supply and distribution online. Disponível em:
<http://www.fas.usda.gov/psdonline/psdQuery.aspx>. Acesso em: 23 fev. 2010.

XUE, Q.; WEISS, A.; BAENZIGER, P. S. Predicting leaf appearance in field-grown winter wheat: evaluating linear and non-linear models. Ecological Modeling, v. 175, n. 3, p. 261-270, 2004. 